\title{
La Inquisición y los infieles: los mineros saxones a finales del siglo XVIII en Nueva España*
}

\author{
por Eduardo Flores Clair
}

\begin{abstract}
This paper intends to analyze one of the most outrageous subjects related to religious intolerance in American territories. The plan of the Spanish crown to hire Saxon miners for the exploitation of American mines is a good example that shows the harassment, reject, and prosecution of all those who did not profess the Catholic religion. At the end of the eighteenth century, the options for these Saxons were the conversion to Catholicism or the maintenance of their own cult, even though this meant an opposition status in society.
\end{abstract}

El interés de este trabajo se centra en analizar a grandes rasgos las dificultades que enfrentó un puñado de trabajadores mineros de origen saxon a finales del siglo XVIII, por el hecho de haber profesado la religión "protestante" en la Nueva España. Este tipo de casos permite conocer algunos aspectos de la vida cultural de la sociedad novohispana y descubrir hasta qué punto se cumplieron las leyes impuestas por el Tribunal del Santo Oficio de la Inquisición. En este sentido, hemos elegido un tema recurrente: la guerra religiosa entre católicos y "herejes". Sobre este problema en particular se ha escrito tanto que casi siempre se corre el riesgo de repetirse. ${ }^{1}$

* Quiero agradecer los comentarios y críticas que me ayudaron en mucho a mejorar este trabajo, al Dr. Jorge Réne González Marmolejo, a la Dra. Renate Pieper y a los dictaminadores del artículo.

1 Consúltese el libro clásico, Solange Alberro, Inquisición y Sociedad en México 1571-1700 (México, D.F. 1988); para una revisión historiográfica véase Jean Pierre Dedieu, "De la inquisición y su inserción social. Nuevas directrices en la historiografía inquisitorial", publicado en línea: http://halshs.archives-ouvertes.fr/docs/00/03/65/99/ PDF/Dd_inquisicion_directrices.pdf. 
Intentaré examinar el caso desde el punto de vista de la teoría del miedo, básicamente a partir de la incertidumbre que causó el enfrentamiento con el "otro", con un ser desconocido, venido de tierras muy lejanas y que el imaginario había construido como un personaje maligno. Asimismo, pondré énfasis en la manera en que se percibía a los extranjeros, en particular a los saxones, en la sociedad novohispana y los mecanismos que utilizaron los "luteranos" con el fin de aprovechar y adaptarse a un medio de convivencia distinto al suyo. ${ }^{2}$ Respecto a la teoría del miedo, retomo la idea de Jean Delumeau, quien escribió que el miedo social "abarca una gama de emociones que van del temor y de la aprensión a los terrores más vivos" y agrega que la fuente del miedo puede ser "real o imaginaria."

Es importante señalar que, sobre la misión de los trabajadores saxones encabezada por Fausto de Elhuyar, director general del Tribunal de Minería, existe una buena cantidad de trabajos que da cuenta de los detalles, procesos, implicaciones, metas y resultados alcanzados. ${ }^{4}$ Pero a pesar de la abundancia, creemos que aún falta mucho por investigar acerca del tema y para ello nos planteamos tres preguntas: 1., ¿cuál fue el impacto religioso que causó entre los mineros saxones la idea de viajar a América?; 2., ¿en qué medida la religión de éstos se convirtió en una amenaza para la sociedad?; y 3., ¿cuáles fueron las estrategias utilizadas para adaptarse a las costumbres novohispanas?

2 Véase Pilar Gonzalbo, "Reflexiones sobre el miedo en la Historia": eadem/Anne Staples/Valentina Torres Septién (eds.), Una historia de los usos del miedo (México, D.F. 2009), p. 32.

3 Jean Delumeau, El miedo en Occidente (Madrid 2002), p. 30.

4 Patricia Aceves, "Intercambios científicos en la Nueva España: una nueva lectura de la Comisión Minera": Alejandro R. Díez Torre/Tomás Mallo/Daniel Pacheco Fernández (coords.), De la ciencia ilustrada a la ciencia romántica, Actas de las II Jornadas sobre 'España y las expediciones científicas en América y Filipinas' (Madrid 1995), pp. 359-376; André Marius, "Le Baron de Nordenflicht, Conseiller intime de S. M. le Roi de Pologne et les mineurs allemands au Pérou": Revue de L'Amérique Latine 3e année, VIII (1924), pp. 289-306; Rose Marie Buechler, Gobierno, minería y sociedad. Potosí y el 'renacimiento' Borbónico 1776-1810 (La Paz 1989); Carlos Contreras, Los mineros del rey: los Andes del Norte, Hualgayoc 1770-1825 (Lima 1995); Renée Gicklhorn, Die Bergexpedition des Freiherrn von Nordenflycht und die deutschen Bergleute in Peru (Leipzig 1963); Bernd Hausberger, "Abbau und Verhüttung von Silbererzen im kolonialen Mexiko. Von Theorie und Praxis industrieller Techniken und Technologien": Österreichische Gesellschaft für Geschichte der Naturwissenschaften 9, 1-2 (1989), pp. 19-51; Marie Helmer, "Mineurs allemands à Potosí: L'expédition Nordenflycht (1788-1798)": VI Congreso Internacional de Minería, Cátedra de San Isidro, vol. I (1970), pp. 513-528, entre otros. 
LOS OTROS

Partimos de los testimonios conservados en los archivos que permiten distinguir que en la sociedad novohispana las personas que profesaban una religión distinta causaban desconfianza, sospecha y hasta temor. Hay que tener en cuenta que, para los ojos de los españoles, quien causaba esa suspicacia era principalmente la población constituida por indígenas (sobre todo por las religiones prehispánicas) y occidentales "protestantes". Se pensaba que todos aquellos que profesaban una religión distinta al catolicismo eran una amenaza contra la fe, atentaban a la moral pública y tenían un estilo de vida que los alejaba de Dios. ${ }^{5}$ Es bien sabido que el Tribunal de la Inquisición fue el encargado de cuidar todos los aspectos religiosos que comprendían la vida de los españoles y americanos. En consecuencia fue el responsable de perseguir y castigar a este tipo de ,herejes“. 6

A grandes líneas, desde el descubrimiento de los territorios americanos, la Corona española impuso una política restrictiva sobre la circulación en territorios americanos a los extranjeros; de hecho, tenían prohibido "ir, estar, o habitar en las Indias". ${ }^{7}$ Según las Leyes de Indias, los pasajeros debían de contar con "licencia" otorgada por el rey o la Casa de Contratación de Sevilla; todos aquellos que eludían este requisito perdían sus bienes y, en su caso, el denunciante adquiría el derecho de disfrutar de la quinta parte de lo incautado. La ley era muy precisa; establecía que todos aquellos oficiales reales que encubrieran algún "pasajero sin licencia" perderían su empleo, bienes y pagarían una multa considerable. ${ }^{8}$

La sociología de los excluidos fue más amplia de lo que uno podría imaginar. En la "lista negra" aparecía que "ningún reconciliado, hijo, ni nieto de quemado, sambenitado, ni hereje" pudiera pasar a Indias. De igual forma se agregaba a "los negros ladinos", "los esclavos blan-

5 Respecto a la leyenda negra de la inquisición véase, entre otros, a Consuelo Maqueda Abreu, "Extranjeros, Leyenda Negra e Inquisición": Revista de la Inquisición 5 (1996), pp. 39-102.

6 Antonio Peñafiel Ramón, "Inquisición y moralidad pública en la España del siglo XVIII”: Revista de la Inquisición 5 (1996), pp. 293-302.

7 Citado por Francisco Javier Gamboa, Comentarios a las Ordenanzas de Minas (México, D.F. 1874), p. 13.

8 Para ahondar más sobre este tema véase en especial el capítulo 3, dedicado a la emigración religiosa, en Charles F. Nunn, Foreign Immgrants in Early Bourbon Mexico 1700-1760 (Cambridge 1979). 
cos y negros", "loros", "berberiscos", "moros", "gitanos" y "mujeres solteras" entre otros. En contraparte, "los indios" y todos aquellos "españoles y mestizos" nacidos en Indias tampoco tenían la libertad para viajar a Europa - también debían de contar con una "licencia". Por más obstáculos que se les impusieron, siempre los europeos, judíos y musulmane ${ }^{10}$ encontraron la manera de eludir el control y se encaminaron al Nuevo Mundo. ${ }^{11}$

Los españoles permitieron que algunos extranjeros viajaran o incluso emigraran a América y llegaron a conseguir "licencia" u obtener "cartas de naturaleza" por la vía legal o a través de la corrupción. ${ }^{12}$ Sin embargo, en ciertos periodos, las leyes se endurecieron; por ejemplo, en 1661, según una real cédula, se estableció que los extranjeros que residían en los reinos de América tenían 40 días para presentarse ante las autoridades locales con el fin de tramitar los permisos de estancia correspondientes, pues, de lo contrario perderían sus bienes y hasta la "vida". ${ }^{13}$ En las actividades económicas, el comercio y la minería fueron los ámbitos más restrictivos, pero fue precisamente en esos negocios donde los ricos "judaizantes" se inmiscuyeron. En términos legales, los extranjeros no debían "avecindarse" ni siquiera en la proximidad de los centros mineros. ${ }^{14}$ Asimismo, se les prohibió buscar minas, poseerlas y comerciar con los productos.

En general, los extranjeros residentes en Nueva España estuvieron vigilados en su comportamiento y sobre todo en sus costumbres. ${ }^{15}$ Hacia el último tercio del siglo XVIII notamos cierta flexibilidad. En

${ }^{9}$ Recopilación de las Leyes de Indias, libro IX, título XXVI, "De los pasajeros y Licencias para ir a Indias, y volver a estos Reinos". Asimismo el título XXVII, "De los extranjeros que pasan a Indias, y su composición, y naturaleza, que en ellas pueda adquirir para tratar y contratar", cuyas estipulaciones son dirigidas principalmente al aspecto económico, sobre todo el comercio y la manera de evitar que se quedaran con los metales preciosos y las perlas.

${ }^{10}$ Fermín Mayorga, "La comunidad judía en Fregenal a finales del siglo XV": Alcántara 67 (2007), pp. 25-88.

11 Demetrio Ramos Pérez, El Mito del Dorado. Su génesis y proceso con el Discovery de Walter Raleigh (Caracas 1973).

12 Véase, entre otros, Isabela Macías Domínguez, La llamada del Nuevo Mundo. La emigración española a América, 1701-1750 (Sevilla 1999); Rosario Márquez Macias, La emigración Española a América, 1765-1824 (Oviedo 1995).

13 Archivo General de la Nación México (en adelante AGNM), Indiferente Virreinal, caja 3339, exp. 12, 1661 .

14 AGNM, Indiferente Virreinal, caja 6389, exp. 18, 1622, 14 fojas.

15 AGNM, Inquisición, vol. 285, exp. 58, 1609, fs. 244-273. 
1776 se expidió un bando donde las condiciones de los extranjeros se modificaron. Desde entonces, los tribunales tuvieron prohibido secuestrar los bienes de "los ajenos", en especial si estaban casados con españolas e indias y habían procreado hijos. ${ }^{16}$ Una política que podríamos considerar de corte "liberal" se impuso en las Ordenanzas de Minería de $1784 .{ }^{17}$ Se estipuló que los extranjeros "naturalizados" y "tolerados" gozarían de los mismos privilegios que los vasallos. Expresado con otras palabras: podían adquirir, poseer y usufructuar los minerales preciosos que explotaran. Aunque hay que reconocer que la desconfianza respecto a los "protestantes" fue un mal crónico. ${ }^{18}$

\section{LA CONTRIBUCIÓN ALEMANA}

Los trabajos generales sobre emigración de Europa hacia América han demostrado que existió una débil presencia alemana, sobre todo en Nueva España. Según Carlos Martínez Shaw, sólo dos alemanes consiguieron una naturalización entre 1750 y 1792, para toda Hispanoamérica. ${ }^{19}$ En cambio, se sabe que la emigración alemana encontró mejores condiciones en los Estados Unidos de América y en el Canadá, donde los emigrantes llegaron a fundar diversas poblaciones. ${ }^{20}$

Pero a pesar de ello, la presencia alemana en las minas de Nueva España fue una constante desde el siglo XVI. Se tiene documentado que las casas comerciales alemanas, como los Fúcaros, tuvieron una participación muy importante en el comercio de metales preciosos

16 AGNM, Indiferente Virreinal, caja 3668, exp. 42, 1776.

17 Ordenanzas de Minería 1784, Ordenanzas de Minería, y Colección de las leyes y Ordenes que con fecha posterior se han expedido sobre la materia, arregladas por el Licenciado José Olmedo y Lama (México, D.F. 1873), p. 19.

${ }_{18}$ Existen algunos casos de extranjeros que recibieron un trato justo en los reales mineros e incluso llegaron a reunir fortunas y otros renunciaron a su religión y se convirtieron. A esta situación debemos señalar que existen cuando menos dos épocas de intensa persecución a los franceses con la invasión Napoleónica y durante la guerra de Independencia. En ambos casos, la Inquisición actuó como un órgano de vigilancia, control y represión.

${ }_{19}$ Carlos Martínez Shaw, La emigración española en América (Colombres 1994), p. 198. Cabe hacer mención que la presencia alemana en México durante el siglo XIX y hasta hoy en día ha ido en aumento. Muestra de ello es el reciente libro Karl Kohut/ Alicia Mayer/Brígida von Mentz/María Cristina Torales (eds.), Alemania y el México Independiente. Percepciones mutuas, 1810-1910 (México, D.F. 2010).

${ }^{20}$ René Le Conte, "Colonisation et émigration allemandes en Amérique": Journal de la Société des Américanistes 14-15, 1 (1922), pp. 83-105. 
americanos e incluso constituyeron empresas para explotar las minas en Maracaibo y Nueva España. Brígida von Mentz, estudiosa de la industria minera novohispana, en un trabajo reciente encuentra diversos paralelismos con el sistema de trabajo en ambas industrias mineras, es decir, la alemana y la novohispana. Dicho intercambio fue gracias a la exportación de conocimientos, agentes culturales y relaciones comerciales, principalmente a través del azogue, mineral vital para la metalurgia en América.

Ante la demanda de trabajadores expertos y debido al interés de introducir el nuevo método de "amalgamación en frio", inventado por el consejero Ignacio Born, se inició una relación entre las Coronas de España y Saxonia. ${ }^{21}$ La aplicación del nuevo método requirió de operarios saxones. Según, Luis Onís, ministro plenipotenciario español de la corte de Saxonia, la contratación fue una "escabrosa y difícil comisión"; tuvo diversas implicaciones en asuntos relacionados con los secretos técnicos, estrategia política social y hasta espionaje industrial..$^{22}$ Las negociaciones se prolongaron entre abril de 1786 y noviembre de 1787 , tiempo en que se llevó a cabo la selección de los trabajadores, enganche y firma de los contratos. Uno de los mayores problemas fue el hecho de que dichos trabajadores profesaran la religión protestante. En los contratos de trabajo, además de estipular las condiciones laborales y establecer una vigencia por diez años, se acordó que la Corona española velaría por la seguridad e integridad de cada uno de los contratados. En especial, respecto a la religión, la Monarquía otorgó el derecho de que "no he de ser molestado, ni se me ha de impedir el uso libre de ella, por ningún Juez, Tribunal, ni bajo pretexto alguno"; del mismo modo, se agregó que el operario no haría proselitismo, con el fin de no perturbar la tranquilidad pública y, sobre todo, adquirió la obligación de respetar los "usos y costumbres" de los americanos. ${ }^{23}$

Por medio de los contratos, la Corona se vio precisada a aceptar la tolerancia religiosa, y los trabajadores fueron exceptuados del fuero

${ }^{21}$ La obra de Ignacio Born, Método de extracción de metales, minerales y otras sustancias metalúrgicas por el mercurio (Viena 1788), adquirió una gran difusión en los círculos académicos de Europa y los incipientes de América.

${ }^{22}$ Archivo de Simancas (en adelante AS), Estado 6578, Correspondencia de Luis Onis, desde Dresden, en relación a la contratación de alemanes y labores de espionaje de Fausto de Elhuyar, 25 de octubre de 1787.

${ }^{23}$ AS, Estado 6579, Borradores de los contratos de los alemanes, elaborados por Luis de Onis, firmado en Freiberg 28 de octubre de 1787. 
del Santo Oficio, el cual no tenía autoridad para procesarlos y mucho menos para someterlos a su competencia. Asimismo, los vasallos americanos se protegían de una posible contaminación y salvaguardaban sus creencias, porque los saxones tenían estrictamente prohibido propagar sus ideas místicas. Existía el enorme temor de que las comunidades fueran muy vulnerables a la propaganda extranjera. Ellos debían de respetar las prácticas religiosas de los reales mineros a los que fueran comisionados.

Es importante apuntar que este tipo de acuerdo tenía una antigua raíz; sobre todo en el mundo de la diplomacia entre las Monarquías europeas. Sólo por citar un ejemplo, podemos decir que en 1604 Inglaterra y España pactaron que los súbditos ingleses no serían molestados por la Inquisición y no estarían obligados a entrar a las iglesias españolas, pero en el caso de que ingresaran "han de mostrar respeto y reverencia". De la misma manera, se aclaró que si los ingleses veían la procesión del Santo Sacramento en las calles ibéricas, "han de venerarlo arrodillándose o meterse por alguna otra calle". ${ }^{24}$ Es decir, siempre hubo manera de establecer ciertas reglas para una convivencia pacífica con el "otro" y evitar las confrontaciones.

El 3 de noviembre de 1787, Luis Lindner encabezó a un grupo de 30 trabajadores que fueron contratados para explotar las minas americanas. Los ciudadanos de Freiberg los despidieron con un gran entusiasmo, organizaron una fiesta amenizada por música y cantos, la población acompañó por las calles a los trabajadores y les deseó buena suerte en su "misión". Los saxones viajaron por varios días por el río Elba, pero debido a un "viento contrario" se detuvieron en la ciudad de Magdeburgo. De manera inesperada, en la noche del 16 de abril, los hermanos "Ramat", ${ }^{25}$ en compañía de "Vischer", aprovecharon el silencio de la noche y se percataron de que todos dormían con el fin de escapar. Al hacerse la investigación sobre la fuga, Lindner informó que el grupo estuvo hablando por largas horas con un joven aduanero de nombre "Schwerin Maklengurg", quien realizó distintas "exclama-

${ }^{24}$ Maqueda Abreu, "Extranjeros, Leyenda Negra e Inquisición” (nota 5), p. 70.

${ }_{25}$ Nos hemos guiado por la grafía de los documentos, tratando de conservar los nombres de los operarios y lugares según fueron escritos por los amanuenses, que en el caso de errores se repitieron a lo largo de la documentación que existe, más de diez años. Estoy conciente de que puede haber omisiones, confusiones o errores, inclusive en los lugares, pero por desgracia no me ha sido fácil identificar con toda precisión tanto los nombres de las personas, así como el de los lugares geográficos. 
ciones" en contra del "gobierno español" y "pintó con colores terribles al Tribunal de la Inquisición”. En la conversación se oyó decir al evadido, Vischer, "que si él hubiera conocido antes esta situación no se hubiera enganchado" 26 .

¿Qué se imaginaron los "huidos" sobre el Santo Oficio? No lo sabemos, pero es posible que hayan pensado que se iban a convertir en los protagonistas de los juicios, las torturas, actos de fe y hasta la hoguera, sólo por el hecho de profesar una religión distinta a la católica. Después de unos días, los mineros fueron aprehendidos y repitieron, una y otra vez, que tenían "miedo" y que en América los protestantes eran perseguidos de "manera espantosa".

De hecho, los saxones fueron presa del terror y a la vez desafiaron el poder de la Monarquía; por ello sufrieron una cascada de infortunios. Los tres tenían familias extensas y la mayoría de sus hijos eran pequeños, su vida quedó marcada casi de la misma manera que las torturas de la Inquisición. Los diplomáticos españoles exigieron a las autoridades saxonas que se les aplicara un "castigo ejemplar". En el momento de la contratación se les había adelantado cierta cantidad de dinero para saldar sus deudas "ancestrales" y les sería imposible recuperarlo debido a la "pobreza" que padecían los trabajadores. Los españoles exigieron que se les resarcieran los gastos y perjuicios que esos hombres les habían causado y pidieron encarecidamente que los fugados jamás fueran contratados en las minas del Elector de Saxonia. Al parecer, las peticiones fueron aceptadas, ya que meses después el embajador, Luís Onis, describió al rey la dramática situación que padecían los fugados. Escribió que en las calles de Freiberg "andan pidiendo limosna". ${ }^{27}$

\section{LOS CONVERSOS}

Cuando la misión llegó al puerto de Cádiz, ${ }^{28}$ tuvieron el primer inconveniente con el Tribunal de la Inquisición. En el equipaje de los saxones se

26 AGI, Indiferente General, 1798, Carta de Luís Lindner a Luis Onis, fechada en Burdeos el 19 de enero de 1788. "Schwerin Maklengurg" es un nombre falso y hace referencia al lugar geográfico "Schwerin Mecklenburg".

27 Archivo General de Indias, Sevilla (en adelante AGI), Indiferente General, 1798, Correspondencia de Luis Onis, 1778-1779.

${ }^{28}$ Enrique Gacto, "El Arte vigilado. Sobre la censura estética de la inquisición española en el siglo XVIII": Revista de la Inquisición 9 (2000), pp. 7-68. 
encontraban baúles con libros - por supuesto, la gran mayoría escritos en alemán y los menos en latín. ${ }^{29}$ Los libros fueron incautados y sometidos al proceso de revisión por los inquisidores. Esta situación alarmó a Fausto de Elhuyar, quien de inmediato buscó el apoyo de los altos funcionarios de la corte, con el fin de que se les permitiera llevar los libros. Argumentó que eran una parte fundamental para mejorar las técnicas mineras americanas. Para su buena fortuna, consiguió que los libros fueran exceptuados de la censura y el incidente sólo fue un sobresalto. ${ }^{30}$

En Cádiz, los trabajadores fueron divididos en tres grupos: uno se dirigió a las minas de Nueva Granada, otro pasó a las minas de Potosí y un tercero a Nueva España. ${ }^{31}$ En el cuadro 1 se pueden apreciar las características generales de los saxones que llegaron al Virreinato de Nueva España, el 14 de agosto de 1788, después de una larga travesía. ${ }^{32}$

Cuadro 1: Mineros contratados por la Corona Española

\begin{tabular}{|c|c|c|c|c|c|}
\hline Clase & Nombres & Natural & Edad & Estado & Religion \\
\hline $1 \mathrm{a}$ & $\begin{array}{l}\text { Don Federico } \\
\text { Soneschmid }\end{array}$ & Jena ducado Weimar & 28 & soltero & protestante \\
\hline $1 \mathrm{a}$ & $\begin{array}{c}\text { Don Francisco } \\
\text { Fischer }\end{array}$ & $\begin{array}{c}\text { Joachimthal } \\
\text { Bohemia }\end{array}$ & 29 & soltero & católico \\
\hline $1 \mathrm{a}$ & $\begin{array}{l}\text { Don Luis } \\
\text { Lindner }\end{array}$ & Schemnitz Hungría & 25 & soltero & católico \\
\hline $2 \mathrm{a}$ & $\begin{array}{c}\text { Don Carlos } \\
\text { Gotlob } \\
\text { Weinhold }\end{array}$ & Brand Saconia & 24 & soltero & protestante \\
\hline $3 a$ & $\begin{array}{c}\text { Juan Gottfried } \\
\text { Vogel }\end{array}$ & Acpendorf Saxonia & 41 & soltero & católico \\
\hline $3 a$ & $\begin{array}{c}\text { Juan Samuel } \\
\text { Suhr }\end{array}$ & Freyber Saxonia & 45 & casado & protestante \\
\hline
\end{tabular}

${ }^{29}$ Una parte de dichos libros puede verse en el apéndice de María Cristina Torales Pacheco, "Apuntes para el estudio de la presencia de la Ilustración alemana en México": Jahrbuch für Geschichte Lateinamericas 40 (2003), pp. 142-150.

${ }^{30}$ AS, Estado 6578.

${ }^{31}$ AGNM, Minería, vol. 48, exp. 7, fs. 217-224v: "Llegada de los operarios Sajones a Nueva España".

${ }^{32}$ El Bando del anuncio de la llegada de los alemanes se publicó en la Gazeta de México III, 19 (29 de octubre de 1788), pp. 177-178. 


\begin{tabular}{|c|c|c|c|c|c|}
\hline Clase & Nombres & Natural & Edad & Estado & Religion \\
\hline $3 a$ & $\begin{array}{l}\text { Juan Samuel } \\
\text { Schroeder }\end{array}$ & Freyber Saxonia & 35 & casado & protestante \\
\hline $3 a$ & $\begin{array}{c}\text { Carlos } \\
\text { Gottlieb } \\
\text { Schroeder }\end{array}$ & Oberschona Saxonia & 29 & casado & protestante \\
\hline $3 a$ & $\begin{array}{l}\text { Juan Christof } \\
\text { Schroeder }\end{array}$ & Erbsdort Saxonia & 34 & casado & protestante \\
\hline $3 a$ & $\begin{array}{l}\text { Carlos F. } \\
\text { Gottfrieb } \\
\text { Weinhold }\end{array}$ & Brand Saxonia & 22 & soltero & protestante \\
\hline $3 a$ & $\begin{array}{c}\text { Juan Gotfried } \\
\text { Adler }\end{array}$ & Freyber Saxonia & 23 & casado & protestante \\
\hline
\end{tabular}

Como se aprecia en el cuadro, existieron tres categorías de trabajadores, teniendo en cuenta sus conocimientos y destreza. Es posible que la mayoría no se conociera, pues eran "naturales" de diversas regiones, pero sí se sabe que se contrató a los hermanos Weinhold y Schroeder. Con la excepción de Juan Samuel Suhr, los mineros se encontraban en su mejor edad productiva. Tanto los solteros como los casados mostraron su conformidad para que se les descontara de su sueldo cierta cantidad con el fin de apoyar a sus familiares por medio de una pensión. Asimismo, debemos resaltar que en el grupo existían cuando menos tres católicos, quienes hacían la diferencia en el mundo de los "protestantes".

Después de trabajar unos meses en las minas novohispanas, sin obtener grandes éxitos en la introducción de las nuevas técnicas europeas, apareció una agradable noticia. En abril de 1790, Juan Samuel Suhr le informó a Fausto de Elhuyar, director general del Tribunal de Minería, que deseaba "abrazar nuestra religión". Suhr solicitó se le instruyera para convertirse al catolicismo. De inmediato, Elhuyar le hizo saber al clérigo de Sombrerete la intención del "infiel" y le urgió que lo "instruyera en los dogmas correspondientes" y lo preparara para hacer "la solemne abjuración". La decisión de Suhr de abandonar su religión fue celebrada con júbilo, e inmediatamente los mineros se la comunicaron al Conde de Revillagigedo, virrey de Nueva España, con la intención de que otorgara su real aprobación. ${ }^{33}$

${ }_{33}$ AGI, Indiferente General 1798, correspondencia de Fausto de Elhuyar, 14 de abril, 1790, Sombrerete. 
Este acontecimiento fue recibido con mucho "regocijo" por la sociedad novohispana, e incluso se publicó una crónica detallada de la ceremonia de retractación en la Gazeta de México. En la reseña se elogió a Suhr por su determinación de abandonar la "secta protestante", "abjurar los errores de Lutero" y abrazar la religión católica. La ceremonia la presidió el obispo Estevan Lorenzo, ${ }^{34}$ el vicario Nicolás de Mijares, Fausto de Elhuyar y el acaudalado empresario José Mariano Fagoaga, quien apadrinó al nuevo católico. De acuerdo a la crónica, por la mañana se reunió la feligresía en la iglesia parroquial, donde además se congregaron, formando una valla, los padres predicadores de Santo Domingo y religiosos frailes de San Francisco, los cuales estuvieron acompañados por el intendente del cabildo. Pero la crónica abunda en otro tipo de pormenores los que nos permiten considerar en su justa dimensión la importancia de ese acto. Todos los eclesiásticos asistieron ataviados con hábitos blancos y pequeños cirios encendidos. Suhr se arrodilló a los pies del obispo e hizo la protesta de fe. Del mismo modo, más adelante en la ceremonia, el iniciado respondió a las preguntas que el prelado le formuló para testimoniar su conversión. La ceremonia era sobresaliente y un ejemplo a seguir. Durante el acto:

“[...] habiéndolo exorcizado y signado con la señal de la Santa Cruz, y demás preces, lo introdujo, tomándole la mano siniestra, hasta la grada inferior del presbiterio, donde dichas las oraciones que previene el pontifical, repitió la protesta de $\mathrm{Fe}$, abjuración de la herejía y profesión de Nuestra Santa Fe Católica, y por no ir dispuesto se difirió la comunión para otro día." ${ }^{35}$

La ceremonia concluyó con una solemne misa, y el pueblo derrochó alegría por tan significativa conversión que había presenciado. El padrino, por su parte, invitó a todos los presentes a su casa, donde fueron agasajados con "un refresco" y un "espléndido banquete". La fiesta fue el marco para ensalzar una conquista significativa. No sólo se le había logrado arrancar un hereje al protestantismo, sino que también se consiguió que ese hombre cambiara para siempre su vida y

${ }^{34}$ Resulta un tanto desconcertante que este obispo haya estado presente, pues a quien le correspondía por jurisdicción era el de Nueva Galicia, pero quizá por cercanía geográfica o por amistad con los empresarios mineros estuvo presente Estevan Lorenzo. Véase AGNM, Indiferente Virreinal, caja 1260, exp. 28, 1790, caja 5696, exp. 60, 1788, caja 6224, exp. 9, 1777.

35 "Sombrerete, 14 de julio": Gazeta de México IV, 15 (10 de agosto de 1790), pp. 142-143. Cursiva en el original. 
quedara protegido por medio del dogma moralmente aceptado en la sociedad novohispana. Sin duda, cobijados por la teatralidad barroca, los "errores" protestantes habían quedado atrás y sepultados. Este hecho abrió la posibilidad de ampliar la conversión a otros miembros de la "misión" y se insistió hasta conseguir más adeptos; aunque para ello los saxones tuvieran que aceptar irremediablemente a la llamada "muerte espiritual". ${ }^{36}$

Dos años más tarde, Juan Gottfried Adler, otro protestante, manifestó su deseo de convertirse al catolicismo. En este caso, su pretensión se debió a una grave enfermedad que lo postró al borde de la muerte. Un médico le dio pocas esperanzas de vida. Sin embargo, por "fortuna" y gracias a "las rogativas", el enfermo consiguió restablecerse y como muestra de agradecimiento decidió convertirse al catolicismo. ${ }^{37}$

Este caso nos lleva a plantear una reflexión mayor en torno a la suerte que le deparaba el destino a los cadáveres de los "infieles". Por una parte, el trabajo en las minas significaba enfrentarse de manera cotidiana a un sinnúmero de peligros y, si a esa situación le sumamos el enfrentarse a la muerte por una grave enfermedad en una tierra de católicos, es fácil imaginar que su deseo de cambiar de religión se debía al hecho de saber que su cuerpo no recibiría sepultura en el campo santo. Adler estaba al tanto de que debido a su religión estaba excluido de reposar en el cementerio. También conocía la suerte de su compañero Juan Gottfried Vogel, quien se había suicidado y se le negó la posibilidad de ser sepultado en el campo santo por dos motivos por ser "infiel" y por haberse "suicidado" - y de cuyo cuerpo se desconocía el paradero. ${ }^{38}$ Por ello, es posible que Adler temiera que su destino fuera más horrendo que la propia muerte: la identidad y memoria de los infieles desaparecía. Los que tenían más suerte terminaban en la fosa común de los ajusticiados, en cuevas, o en el campo y simplemente los cuerpos quedaban al intemperie. En otras palabras, una vez que morían, esos cuerpos tenían el más incierto destino que uno se puede imaginar. A pesar de todo, aquellos que se convirtieron al catolicismo, aún en el último suspiro, adquirieron así la garantía y

${ }^{36}$ En 1793 Juan Samuel Schroeder decidió abandonar el luteranismo y abrazó la religión católica.

37 Tal fue el arrepentimiento de Adler que poco tiempo después le permitieron contraer nupcias por "nuestra iglesia".

38 AGNM, Minería, vol. 26, exps. 10 y 11. 
el derecho de que sus restos mortales tuvieran una mejor suerte..$^{39}$ De hecho era una manera de resistirse a ser borrados de la memoria de la sociedad que los había visto vivir y morir. El entierro era un rito social cargado de un simbolismo particular que, además de la religión que se profesaba, reflejaba "el status social, la condición étnica y jurídica del enterrado". ${ }^{40}$

Otro de los conversos fue Carlos F. Gottfrieb Weinhold, quien también renunció a sus "errores luteranos", aunque sus motivos fueron muy distintos a los de sus paisanos. Sus sentimientos personales se impusieron a su convicción religiosa. De hecho, solicitó permiso para contraer matrimonio con doña Joaquina Ximénez, quien pertenecía

"[...] a una de las mejores casas de esta vecindad teniendo por parientes muy cercanos al Provisor y Doctoral actual, y otros doctores y licenciados matriculados en este ilustre y Real Colegio de Abogados".

Joaquina era hija del difunto corregidor de Xalapa, don Joaquín Ximénez Morras. En virtud de esa situación tanto la madre de la prometida como sus familiares vieron con buenos ojos al extranjero y autorizaron el matrimonio. ${ }^{41}$

En este caso se desconoce hasta donde el matrimonio con una católica apartó a Weinhold de la posibilidad de regresar a Freiberg e incorporarse a su antigua familia y amistades. Lo que sí se sabe es el hecho de que los saxones que se casaron en la Nueva España nunca regresaran a Europa y mucho menos los hijos que llegaron a procrear. El matrimonio de dos personas que profesaban una fe distinta era un yugo desigual. No obstante, los católicos también interpretaron estos hechos como un nuevo triunfo contra "los infieles": se ganaba uno más a la causa de la Iglesia. Pero también, podemos suponer que el

${ }^{39}$ El rito entre los judíos, en general, era el siguiente: las personas que agonizaban las volteaban a la pared para morir, después el cadáver lo lavaban con agua caliente, le cortaban la barba y le afeitaban las axilas, lo amortajaban con un lienzo nuevo, lo vestían con calzones, camia y capa. Entre otras cosas, le ponían en la cabeza una almohada con tierra virgen, en la boca una moneda, derramaban el agua de los cantaros y comían pescado y aceitunas y rechazaban la carne.

${ }^{40}$ Gabriela Caretta/Isabel Zacca, "Lugares para la muerte en el espacio meridional andino, Salta en el siglo XVIII: The Southern Andean Region, Salta 18th Century": Memoria americana 15 (2007), pp. 135-154, publicado en línea: http://www.scielo.org. ar/scielo.php?script=sci_arttext\&pid=S1851-37512007000100005.

${ }^{41}$ AGNM, Minería, vol. 30, exp. 2, fs. 8-15. 
matrimonio fue un mecanismo que utilizaron los saxones con el fin de adaptarse a las costumbres de la sociedad novohispana. Aunque seguramente el convertirse al catolicismo nunca fue un paso fácil, tengo la impresión de que preferían la tranquilidad que les aseguraba su nueva religión que vivir con el temor de la persecución y en algunos casos la pérdida de sus propiedades e incluso verse amenazados de muerte. Así pues, los motivos que los llevaron a tomar la determinación no siempre respondieron a las mismas causas. En algunas ocasiones, el interés que incidió en esos hombres fue el de hacer una alianza matrimonial ventajosa, proteger su patrimonio e, incluso, la práctica de su antigua religión nada más que a partir de su "conversión" al cobijo del catolicismo; para lo cual tuvieran que sacrificar su identidad.

EL JUICIO

Por los registros del Santo Oficio conocemos la averiguación que se realizó contra otros dos protestantes Luis Lindner y Carlos Gottlob Weinhold. En abril de 1791, don Sebastián Sánchez, vecino de Santa María, denunció ante Francisco del Pomar, notario del Santo Oficio en la ciudad de Oaxaca, a los saxones antes mencionados. Manifestó que en un "corrillo" en que se discutía la virginidad de las mujeres, los referidos pusieron en tela de duda la "virginidad de la Santa Virgen". Pero Sebastián sabía que a dichas personas "no se les ha de tratar en puntos de religión, sino dejarlos en libertad que sigan la que quisieren".

A pesar de ello, la denuncia procedió, y el presbítero Agustín Ledos, originario del puerto de Santa María en España, se encargó de aportar un nuevo testimonio. Declaró con el fin de "satisfacer los clamores" que existían en aquella población, que en la huerta de don Blas Gómez se encontraban conversando "los dos alemanes". A ambos se les consideraba "protestantes", aunque sospechaba que Lindner era católico, pues asistía a la iglesia y pasaba "largo tiempo hincado de rodillas delante de los altares, [con] modestia de semblante y compostura en su conversación" y cuando lo veía en misa se le notaba su "fervor cristiano". No obstante, en la conversación referida había puesto en entredicho la "virginidad de las mujeres comunes" y se había comentado "a la santa virgen, teniendo por dudosa su virginidad con esta proposición, no hay moza doncella y aún dudo que la santí- 
sima virgen tuviera virgo". Finalmente, el presbítero Ledos aseguró que al protestante de origen "alemán" no le tenía odio ni mala voluntad y juró guardar secreto.

Del mismo modo, en el expediente aparece el testimonio de Sebastián de la Torre, oficial y supernumerario de la aduana, soltero de 26 años, que vivía en la misma oficina de la aduana. De la Torre compareció ante Sebastián Sánchez Pareja, chantre de la catedral. En esa ocasión el prelado catedralicio le preguntó si había oído decir alguna cosa o un hecho contra "Nuestra Santa Fe". Sebastián le respondió que había escuchado a Carlos, "el alemán", decir que "no alcanzaba cómo podía haber quedado la santísima virgen, después de haber parido". Y que don Luis preguntó:

“¿que si ponía en duda que la santa virgen hubiera tenido comercio carnal con algún hombre o que sólo se interesaba en poner a la vista la oscuridad de encontrados dictámenes con que se explican los físicos el asunto?”.

A pesar de la poca claridad en el testimonio, el dicho Sebastián agregó que don Carlos jamás había dudado de la pureza de la virgen. El 11 de julio, el fiscal inquisidor dio su veredicto ante las diligencias realizadas. En primer lugar expresó que los testigos son de "oídas", es decir, que sólo habían escuchado una conversación de los denunciados en una huerta. De alguna manera el fiscal apoyó lo dicho por Carlos Weinhold en el sentido de que "no comprendía o no alcanzaba [a entender] como María Santísima pudo quedar virgen después de haber parido". Para sustentar su idea, el inquisidor señaló que no había elementos para pensar que Lindner "no creyera". Él consideró que la conversación no era "herética en sí misma", además agregó que por que "los misterios por eso lo son, por que no los alcanzamos: en boca de uno que públicamente [sea] tenido por no católico y venido del reino como que se hace más sospechosa" y concluyó que "no hay fundamento positivo para continuar con los procedimientos". ${ }^{42}$

Resulta un tanto desconcertante observar que el inquisidor consideró que no existía "blasfemia", ni se trataba de una conversación herética, mucho menos que era un dicho en contra de la fe..$^{43}$ Aunque se trata de una breve indagatoria, nos permite contemplar de cerca la

42 AGNM, Inquisición, vol. 1304, exp. 8, 1791.

${ }_{43}$ Es posible que el inquisidor siguiera una máxima de San Pablo, que decía: “[...] que no juzga la Iglesia a los que están fuera del gremio". En Manual de Inquisidores para uso de la Inquisición en España y Portugal (Montpelier 1821), p. 102. 
actitud del Santo Oficio ante el comportamiento de los mineros saxones. Por lo que asienta en el documento es factible suponer que la Inquisición, antes de emitir su sentencia, tuvo en consideración el compromiso del rey, respecto a que a los saxones no se les juzgaría por tribunal alguno y se les permitiría profesar su religión. La mayoría de los testigos eran eclesiásticos, aunque tuvieron la colaboración de los pobladores, quienes se mantenían al tanto de las costumbres de los saxones, pues no se perdían de ningún detalle y hasta se enteraban de sus conversaciones.

En el caso de Luis Lindner, católico como se señala en el cuadro 1, es posible que les haya provocado cierto desconcierto, pues, a pesar de ser extranjero, tenía un comportamiento similar a todos los de la comunidad, sobre todo cuando se encontraba en el interior de los templos y realizaba las mismas prácticas religiosas, pero quizá no comulgaba, pues ni los testigos y tampoco los eclesiásticos hacen referencia de ello. Al parecer, los clérigos se vieron en la necesidad de atender los "clamores" de la población, pues tenían la obligación de enterar a los inquisidores de las denuncias que recibían. En este caso, casi estoy seguro de que, esas mismas blasfemias, en la boca de cualquier católico, hubieran sido causa para abrirles un proceso y castigarlos con toda severidad. Negar el virgo de la virgen se traducía en un ataque peligroso a uno de los principales dogmas de la Iglesia. Este acto ponía en entredicho sus principios y ponía en riesgo preceptos de capital importancia para la religiosidad de los fieles, quienes podían imitar ese mal ejemplo y contaminar al resto de la feligresía. Pienso que esta denuncia se cubrió con el velo del silencio. Pero no sólo eso: de acuerdo con el procedimiento inquisitorial, al no proceder la denuncia los implicados tuvieron conocimiento de la causa que se les había abierto, con lo cual debieron tomar precauciones al expresar sus ideas y reprimir su comportamiento. Es posible suponer que por lo menos durante algunos años estuvieron vigilados.

\section{A MANERA DE CONCLUSIÓN}

El miedo a los extranjeros se expresó de manera dual. Por una parte, la comunidad tuvo temor del "forastero", pero dicho temor se multiplicó en el caso de todos aquellos que profesaban una religión distinta. En más de una ocasión se les identificó como herejes y hasta con tener 
comportamientos diabólicos. Pero el caso demuestra que los protestantes saxones también vivieron inmersos en el miedo. No desconocían la severidad de cómo actuaban los inquisidores contra las personas que habían osado asumir una conducta ajena a los cánones establecidos por la Iglesia. El Santo Oficio del último tercio del siglo XVIII no era muy distinto en comparación con los siglos anteriores. Los aires de la Ilustración y los cambios políticos de las Monarquías europeas en apariencia abrieron la posibilidad de modificar su ámbito, pero en el momento necesario se recurría de nueva cuenta a las antiguas prácticas. ${ }^{44}$ No obstante, mantuvieron incorrupto el sistema de vigilancia por medio de informantes y confesiones en secreto. De esa manera, la religión podía continuar siendo un instrumento de control social. ${ }^{45}$ Como bien afirma Antonio Peñafiel Ramón, la Inquisición no sólo se encargaba de los problemas de la fe, sino también de "todo cuanto pudiera ser tachado de inmoral". ${ }^{46}$

A los conversos jamás se les dejó de vigilar; se puede decir que fueron sospechosos perpetuos. Y las desconfianzas podían aumentar si se descubrió que comían carne en los días que no estaba permitido. También bañarse en ciertos días, lavar la ropa, prender velas, decir plegarias en otro idioma, leer libros y una serie de otras conductas podían convertirse en sospechas, acusaciones directas y purgar ciertos castigos, por descuido. No me cabe ninguna duda de que los nuevos católicos buscaron adecuarse a las conductas y costumbres de la sociedad, en este caso la novohispana, para lo cual adoptaron varias vías, desde la posibilidad de renunciar a su religión hasta contraer matrimonio. En la Gaceta Diaria de México en 1826 todavía se afirmaba que la sociedad tenía la idea de que "extranjeros y enemigos eran sinónimos" y aún más si "el extranjero era hereje". ${ }^{47} \mathrm{Al}$ parecer, casi hasta nuestros días, los extranjeros siempre levantan suspicacias de que sus intenciones no son buenas.

44 "Descripción de un acto de Fé": Gazeta de México VII, 46 (21 de agosto 1795), pp. 390 y ss.

45 Según Ángel Rodríguez Sánchez, "La soga y el fuego. La pena de muerte en la España de los siglos XVI y XVII": Cuadernos de Historia Moderna 18 (1997), pp. 51-67, la Inquisición se encargó de producir terror.

${ }^{46}$ Idem, "Inquisición y moralidad pública en España en el siglo XVII": Revista de la Inquisición 5 (1996), pp. 293-302, aquí: p. 293.

47 Gaceta Diaria de México 2, 32 (1 de febrero de 1826), pp. 3-4. 
En cierto sentido, algunos de los saxones pudieron adecuarse a las nuevas circunstancias y se involucraron en las prácticas culturales de la sociedad novohispana. Pero debemos reconocer que el proceso de "adaptación de los conversos" fue lento, pues era imposible pensar que de la noche a la mañana los infieles iban a borrar de su memoria conductas, costumbres y prácticas religiosas. Por más extraordinarias ceremonias que se les hiciesen, había muchos aspectos de la vida que había que modificar y otros seguramente se los guardaban para no perder sus rasgos de identidad.

El mantenerse infiel en tierra de católicos fue un quehacer difícil de cumplir en diversos aspectos de la vida: en términos de la movilidad social, en la convivencia cotidiana y hasta en un plano sentimental. De hecho, aunque eran tolerados, estaban excluidos, sin aceptación plena. Empero, su situación se tornó todavía mucho más compleja durante su agonía y muerte. Se sabían alejados de su familia y sin poder compartir el último suspiro con sus seres queridos. Quizá por esa razón, entre otras muchas y algunas de las cuales he referido a lo largo de este trabajo, les resultaba más alentador cambiar sus creencias que padecer el terror de la marginación. La sociedad logró comprobar que los saxones estaban lejos de ser unas personas diabólicas y que tenían más semejanzas que diferencias, tanto así que algunos de ellos lograron contraer nupcias y procrear hijos. La gran mayoría no volvió a ver los valles verdes y apacibles de Freiberg, y sus restos quedaron en las tierras lejanas de Nueva España. 